\title{
Clinical outcomes and complications of treatment with supraflex stent in patients with coronary artery disease: One-year follow-up
}

\author{
Zahra Sharifi (1), Majid Jalal Yazdi (2), Ali Eshraghi (1), Vida Vakili (3), Javad \\ Ramezani (2) \\ (1) Student Research Committee, Mashhad University of Medical Sciences, Mashhad, Iran; (2) \\ Department of Cardiology, Faculty of Medicine, Mashhad University of Medical Sciences, \\ Mashhad, Iran; (3) Department of Community Medicine, Mashhad University of Medical \\ Sciences, Mashhad, Iran.
}

This article is distributed under the terms of the Creative Commons Attribution Noncommercial License (CC BY-NC 4.0) which permits any noncommercial use, distribution, and reproduction in any medium, provided the original author(s) and source are credited.

\begin{abstract}
Cardiovascular disease is one of the most important causes of morbidity and mortality in the world. Treatment in most patients is percutanseous coronary intervention. One of new generation drug-eluting stent (DES) is Sirolimus Eluting Stent. The current study was aimed to investigate the clinical outcomes and complications of treatment with supraflex stent during one year follow up in patients with coronary artery disease. This cross-sectional study was performed on patients with myocardial ischemia who were candidate for coronary angioplasty between $2017-2018$ in Imam Reza Hospital, Mashhad, Iran.. Patients were followed for four primary end points including Target lesion revascularization (TLR), stent thrombosis (ST), myocardial infarction (MI) and cardiac death (CD) for one year. Descriptive data were analyzed by Freidman at a significance level of 0.05 . A total of 287 patients were enrolled in the study. There was no TLR, MI, ST and CD records in the one month follow up. Six months follow up demonstrated three TLR patients and three MI patients, but no ST and death were reported. After one year follow up, three cases of CD and four ST cases were found in patients treated with supraflex stent. Based on the Freidman test, the highest rate of TLR was revealed in a six-month follow-up when comparing with one-month and twelve-month follow-up $(p=0.05)$. No significant relationship was found between the other cases. The most common complications associated with supraflex stent were TLR and MI in six-month follow-up. The most likely occurrence of CD and ST were found in one year follow up.
\end{abstract}

Key Words: Angioplasty, drug-eluting stent, Sirolimus Eluting Stent, clinical outcome.

Eur J Transl Myol 29 (2): 136-142, 2019

Today, coronary heart disease is one of the most important causes of morbidity and mortality worldwide. ${ }^{1}$ In recent decades, the development of vascular intrervention has led to significant improvement in the outcomes of the treatment. ${ }^{2}$ Since the first vascular interventions, major changes have occurred in techniques and technologies involved in percutaneous transluminal coronary angioplasty, so that, apart from the balloon angioplasty, stent insertion for vascular interventions is currently used to be potentially capable of reducing restenosis and reducing ischemic recurrence and preventing coronary artery remodeling. ${ }^{3}$ Currently, preferred treatment for revascularization is percutaneous coronary interventions (PCI), except in selected cases including left main coronary artery stenosis or stenosis of multiple vessels. However, after using Stent, there is still a possibility of re-narrowing due to intima hyperplasia within the stent, especially with the use of conventional bare metal stents. ${ }^{4}$. For this reason, drug-eluting stent (DES) which had a significant effect on the reduction of restenosis gradually replaced bare stents over the years. The first generation DES using a durable polymer-based stent has used the gradual release of Sirolimus or Paclitaxel, resulting in a significant reduction in target lesion revascularization (TLR) compared to bare metal stents. ${ }^{5,6}$ Several human and animal studies, in particular using autopsy data, found that durable polymers were a stimulant for chronic inflammatory and hypersensitivity reactions that plays an important role in increasing the incidence of late stent thrombosis (ST) and late in-stent restenosis due to endothelialization in strata, late arterial healing and disturbances in coronary dynamics. ${ }^{7-12}$ For 
this reason, the next generation of DES was made up of Bioabsorbable and Biocompatible polymers, and their characteristics were the lack of stimulants that could cause inflammation. ${ }^{13}$ The new generation of polymers is that polymer does not remain at the site of the stent after the new intima hyperplasia period. Consequently, the anti-restenotic elements are secreted in a controlled manner and then the coating is gradually decomposed. ${ }^{4,14}$ Studies have shown that drug stents containing biodegradable polymers have been more effective than bare metal stents that have been associated with a reduced risk of late ST, even when compared to first-generation DES. Of course, the efficacy and relative efficacy of biodegradable polymer stents have not yet been fully elucidated and have not had enough power studies to determine their differences in deaths, cardiac deaths, myocardial infarction (MI) and ST and the level of target vessel revascularization (TVR). The sirolimus-eluting stent (Supraflex) is a DES that releases Sirolimus. On the Flexinium stent platform, supralimus is embedded as a decomposable polymer.

\section{Materials and Methods}

\section{Patients}

This prospective cross-sectional study was conducted to evaluate all patients undergoing angiography and angioplasty during the 2017-2018 in the heart department of Imam Reza Hospital. Inclusion criteria were; patients over the age of 18 with evidence of myocardial ischemia who were candidates for angioplasty according to the American College of Cardiology/American Heart Association (AHA)/European Society of Cardiology (ESC) guidelines. Exclusion criteria included patients who used other stents in addition to the supralimus stent during the procedure. The study has been approved by the Ethics Committee of Mashhad University of Medical Sciences and all enrolled subjects have been informed by obtaining written consent before entering the study. For angiography and stenting, local anesthesia was performed and patients underwent coronary angiography through the femoral artery or right radial artery. In this way, the catheter of the femoral artery entered the aorta and placed in the coronary entrance. In the next step, the iso-osmolar contrast agent was used at 50 to $100 \mathrm{cc}$. The assessment of the stenosis was based on the visual assessment by the operator. Significant stenosis (in the sense of stenosis of more than $70 \%$ of lumen) was considred for stenting. After the procedure, postdilatation was also performed for most patients. During the procedure, all patients received anti-coagulant (heparin), while the use of glycoprotein IIb/IIIa inhibitors during the procedure was based on the operator's decision. All patients received dual antiplatelet therapy (loading dose - aspirin clopidegrel) and their use continued after 1 year of stent placement. Other drugs like statin, beta-blocker (angiotensin converting enzyme) and antihypertensive drugs were prescribed to all patients according to AHA and ESC guidelines. After PCI, all patients were monitored accurately for any type of complication related to the procedure during hospitalization. Exclusion criteria including stent underexpansion, margin dissection, and incomplete wall apposition were assessed in all patients. In case of occurrence of each of them, the patient was excluded from the study. After discharge, all patients were thoroughly examined at intervals of 30 days, followed by every 3 months of visitation. Meanwhile, by providing clear explanations about the disease, patients were asked to contact their physician in case of any cardiovascular event and other complications. All patients were

Table 1. Demographic information of patients

\begin{tabular}{lcc}
\hline Valve clash & 2 & 0.7 \\
\hline Hypertension & 105 & 36.6 \\
Dislipidemia & 102 & 35.5 \\
Smoking & 43 & 15 \\
Diabetes & 51 & 17.7 \\
Kidney function status & & \\
$\quad$ (GFR>90) Stage 1 & 18 & 6.3 \\
(GFR60-89) Stage 2 & 237 & 82.6 \\
(GFR 45-59) Stage 3a & 26 & 9.1 \\
(GFR 30-44) Stage 3b & 6 & $1 / 2$ \\
(GFR 15-29) Stage 4 & 0 & 0 \\
(GFR < 15) Stage 5 & 0 & 0 \\
The disease leads to angioplasty & & 37.9 \\
chronic CAD & 108 & 35.8 \\
unstable angina & 102 & 14 \\
STEMI & 40 & 12.3 \\
NSTEMI & 35 &
\end{tabular}




\begin{tabular}{|c|c|c|}
\hline Variable & Frequency & Percent \\
\hline \multicolumn{3}{|l|}{ Lesion type } \\
\hline A & 42 & 14.6 \\
\hline B1 & 71 & 24.7 \\
\hline B2 & 100 & 34.8 \\
\hline $\mathrm{C}$ & 40 & 13.9 \\
\hline Proximal & 2 & 0.7 \\
\hline A+ Proximal & 6 & 2.1 \\
\hline B1+ Proximal & 6 & 2.1 \\
\hline$A+C$ & 1 & 0.3 \\
\hline $\mathrm{B}+\mathrm{C}$ & 10 & 3.5 \\
\hline Proximal B2+ & 9 & 3.1 \\
\hline \multicolumn{3}{|l|}{ Name of the main vessels involved } \\
\hline RCA & 79 & 27.5 \\
\hline Left circumflex artery (LCx) & 25 & 8.7 \\
\hline LAD & 121 & 42.2 \\
\hline Obtuse marginal (OM) & 31 & 10.8 \\
\hline $\mathrm{RCA}+\mathrm{LCx}$ & 6 & 2 \\
\hline RCA+LAD & 18 & 6.3 \\
\hline $\mathrm{LAD}+\mathrm{LCx}$ & 2 & 0.7 \\
\hline $\mathrm{LAD}+\mathrm{OM}$ & 2 & 0.7 \\
\hline \multicolumn{3}{|l|}{ Number of vessels involved } \\
\hline One & 184 & 64.1 \\
\hline Two & 71 & 24.7 \\
\hline Three & 32 & 11.1 \\
\hline \multicolumn{3}{|l|}{ Number of stents } \\
\hline One & 220 & 76.7 \\
\hline Two & 60 & 20.9 \\
\hline Three & 7 & 2.4 \\
\hline Post dilatation & 184 & 64.1 \\
\hline Bypass graft & 2 & 1.7 \\
\hline CAD remains & 86 & 29.9 \\
\hline \multicolumn{3}{|l|}{ Severity of stoning remains in CAD } \\
\hline mild & 26 & 30 \\
\hline moderate & 27 & 31.3 \\
\hline Severity & 33 & 38.3 \\
\hline PPCI & 16 & 5.6 \\
\hline FPCI & 15 & 5.2 \\
\hline
\end{tabular}

followed up with clinical signs or cardiovascular events, requiring angiography according to guidelines.

In this study, four primary end points were defined as follows: TLR implies the need for revascularization on the stent location, or at a distance of $5 \mathrm{~mm}$ from its proximal and distal margins, if the patient is symptomatic. Definite ST is defined as the stent path obstruction, and the symptomatic thrombotic event as MI diagnosed with coronary angiography.

\section{Sample size and statistical analysis}

The sample size was calculated by considering the outcomes of cardiac death, non-lethal cardiac infarction, revascularization due to clinical symptoms and ischemia. The sample size was calculated as 288 people using the formula $(\alpha=5.00 \%, P=25.00 \%, d=5.00 \%)$.

$$
n=\frac{\left(z_{1-\alpha / 2}\right)^{2} p(1-p)}{d^{2}}
$$

The data were entered into SPSS23 software. In describing the data, frequency tables and charts, as well as mean and standard deviation were used. Freidman test was used at a significant level of 0.05 .

\section{Results}

A total of 287 patients were enrolled in the study. The median age of the patients under study was determined as 57 years old (37-88). The most common cause of angioplasty was fond to be chronic coronary artery disease (CAD) (37.9\%) and unstable angina (35.8\%). Table 1 shows the demographic data of patients. The type of lesion in most patients was type C $(34.8 \%)$ and B1 $(24.7 \%)$. In addition, in most cases of vessel involvement, it was related to (left anterior descending) 


\begin{tabular}{|c|c|c|c|}
\hline & One month (n) & six months (n) & twelve months (n) \\
\hline TLR & 0 & 3 (1percent ) & 3 (1percent ) \\
\hline MI & 0 & 3 (1percent $)$ & 3 (1percent ) \\
\hline defenite ST & 0 & 0 & 4 (1percent ) \\
\hline CD & 0 & 0 & 3 (1percent ) \\
\hline
\end{tabular}

LAD (42.2\%) and right coronary artery (RCA) (27.5\%). A single stent has been used in $76.7 \%$ of patients (Table 2 ). The final thrombolysis in myocardial infarction scores were determined in most patients $(99.3 \%)$. No cases of TLR, MI, definite ST, and CD were reported based on an one-month follow up. In the follow up of six months, three patients showed TLR and three MI, but no cases of definite ST and death were reported. After one year follow up, three cases of CD and four definitr ST cases were observed in patients treated with supraflex stent (Table 3). Based on the Freidman test results, the highest TLR was observed in six-month follow-up as compared to follow-up of one month and twelve months $(\mathrm{p}=0.05)$. There was no significant relationship between the other cases.

\section{Discussion}

Cardiovascular disease is one of the most important causes of morbidity and mortality in the world, ${ }^{1}$ and in Iran. ${ }^{15}$ Treatment is often a percutaneous coronary intervention. The new generation of stents is the Sirolimus Eluting stent. The aim of this study was to investigate the clinical outcomes and complications of treatment with supraflex stent during one year follow up of patients with coronary artery disease. The results of this study demonstrated that none of the outcoms in the follow up was observed in patients. Six months follow up revealed 3 TLR patients and 3 MI patients, but no definitr ST and death were reported. After one year follow up, three cases of CD and four definite ST cases were found in patients treated with Supraflex stent. The highest TLR occurred in the six-month follow-up compared to one month and twelve-month follow-up. There was no significant relationship between the other cases. In the early studies on durable polymer of a DES, a brief increase in the risk of ST was found as compared with bare-metal stents, especially in patients with high comorbidity; additionally, these complications have been more prominent in patients with multiple vessel involvement and bifurcation lesions with many problems. ${ }^{16-19}$ Materials used in the manufacture of durable polymers, that have been placed with the aim of controlled drug release in those stents have led to numerous pathophysiological processes, resulting in chronic inflammatory response and ultimately play a role in ST. This chronic inflammatory response causes stent endothelialisation, stable sedimentation of the clot components, including fibrin and platelets, vascular dysfunction, and thrombosis, which ultimately accompanies vascular remodeling. ${ }^{20-22}$ Biodegradable- polymer drug-eluting stents are designed to eliminate concerns about the persistent complications caused by the presence of durable polymers, durable polymer-based stents. Multiple clinical trials have shown the proper efficacy and minimal complications of this group of stents, which has been shown to have positive clinical effects in long-term follow-up. ${ }^{23,24}$ The usefulness of biodegradable polymer drug-eluting stents is primarily due to events that are ultimately accompanied by a longterm ST (1-4 years). In contrast, the same action has been reported on the effects of both types of biodegradable and durable stents in events occurring with ST in the first year as well as events that are not related to ST. ${ }^{24}$ As a matter of fact, it can be concluded that biodegradable polymer drug-eluting stents are associated with improved longterm treatment outcomes. Overall, the results of this study were similar to previous studies regarding the incidence of CD. Previously, a clinical trial evaluated the use of a biolimus-eluting stent in comparison with sirolimus-eluting stent for coronary revascularization (LEADERS). The results showed that the cumulative incidence of $\mathrm{CD}$ in the follow up of 6 and 9 months was 1 and $2 \%$ respectively, which was in line with the results of the present study. ${ }^{23}$ The rates of MI, ST, and TLR in the current study were lower than that of previous study. ${ }^{23}$ The long-term results of a study by Stefanini et al. indicated that the incidence of ST in a long-term follow up was $0.6 \%$ using biodegradable polymer drugeluting stents, ${ }^{24-26}$ which is consistent with the present study. Regarding the one-year follow up of the patients in this study, the incidence of ST was determined as $1 \%$. Regarding the incidence of ST, the findings of the current study are similar to those observed in previous studies. Along with stents that use biodegradable polymer systems, the newer generation of durable polymer drugeluting stents have been developed that, unlike the durable polymer sirolimus-eluting, as well as paclitaxel eluting, have been accompanied by a clear decrease in ST. A new generation of durable polymer stents, the Durable polymer everolimus-eluting stent, has been shown to reduce ST cases when compared to the paclitaxel-eluting stent. ${ }^{27,28}$ Despite the fact that the proper performance of the new generation of durable polymer stents has been identified, but the results of several clinical trials such as LEADERS, ${ }^{24}$ ISARTEST $3,{ }^{29}$ and ISAR-TEST $4,{ }^{30}$ all indicated a significant improvement in the outcomes of treatment using Biodegradable-Polymer Drug-Eluting Stent that used Biomatrix Flex and ISAR stents, respectively. Regarding the incidence of TLR, the present study revealed that 
three patients suffered from this complication in six months after the insertion of the stent, with a frequency of $1 \%$. The results of a clinical trial (ABSORB) by Ormiston et al. on the use of Cypher bioabsorbable everolimus-eluting coronary stent system are consistent with the results of the present study, which indicates a very small incidence of TLR in a one-year follow-up of patients. ${ }^{31}$ The TLR in the clinical trials of LEADERS, ${ }^{24}$ was determined as $10 \%$, followed by $8 \%$ in an ISARTEST 3 study, ${ }^{29}$ and $12 \%$ in a ISAR-TEST4 study, ${ }^{30}$ was $12 \%$. The incidence of complications and observational events following the use of stents in different studies and clinical trials cannot be compared directly. In a DESSOLVE II study, ST and Major adverse cardiac events have been reported at very low levels in patients treated with bioabsorbable polymer-coated sirolimuseluting stents. ${ }^{32}$ In a study conducted by Abhyankar et al. in 2018, 346 patients treated for a minimum of 7 years with a suprolimus biodegradable polymer coated sirolimus-eluting stent, that CD and TLR levels were attributed to $7 \%$ and $4 \%$, respectively ${ }^{233}$

In summary, results of the current study indicated that none of the patients' outcomes were observed in one month follow-up. Six months follow up showed three TLR patients and three MI patients, but no ST and death. After one year follow up, three cases of CD and four ST cases were observed in patients treated with Supraflex stent. The highest TLR occurred in the six-month followup in comparison with one month and twelve-month follow-up. There was no significant relationship between other cases. The most common complications with Supraflex stent were revealed to be the TLR and MI in six months follow up. The most likely occurrence of CD and ST was observed in one year folow up.

\section{List of acronyms}

AHA - American Heart Association

CAD - Coronary artery disease

CD - Cardiac death

DES - Drug-eluting stent

ESC - European Society of Cardiology

GFR - Glomerular filtration rate

LAD - Left anterior descending

LCx - Left circumflex artery

MI - Myocardial infarction

NSTEMI - Non-ST segment elevation myocardial infarction

OM - Obtuse marginal

PCI - Percutaneous Coronary Intervention

RCA - Right coronary artery

Supraflex - Sirolimus-eluting stent

ST - Stent thrombosis

STEMI - ST-segment elevation myocardial infarction

TLR - Target lesion revascularization

\section{Authors contributions}

All named authors played a substantial role in the conception and/or study design, data acquisition and/or analysis, as well as drafting of the manuscript, approval of the final version to be published, and agree the accountability for all aspects of accuracy and integrity of the work.

\section{Acknowledgments None.}

Funding No funding was obtained for this research project.

\section{Conflict of Interest}

The authors declare they have no financial, personal, or other conflicts of interest..

\section{Ethical Publication Statement}

We confirm that we have read the Journal's position on issues involved in ethical publication and affirm that this report is consistent with those guidelines.

\section{Corresponding Author}

Javad Ramezani, Department of Cardiology, Faculty of Medicine, Mashhad University of Medical Sciences, Mashhad, Iran Tel: 00989155159422

Email: ramezanij@mums.ac.ir

E-mails of co-authors

Zahra Sharifi: SharifiZ941@mums.ac.ir Majid Jalal Yazdi: Jalalyazdim@mums.ac.ir

Ali Eshraghi: EshraghiA@mums.ac.ir

Vida Vakili:VakiliV@mums.ac.ir

\section{References}

1. Sanchis-Gomar F, Perez-Quilis C, Leischik R, et al. Epidemiology of coronary heart disease and acute coronary syndrome. Ann Transl Med 2016;4:256. doi: 10.21037/atm.2016.06.33. Review.

2. Mohr FW, Morice M-C, Kappetein AP, Feldman TE, Ståhle E, Colombo A, et al. Coronary artery bypass graft surgery versus percutaneous coronary intervention in patients with three-vessel disease and left main coronary disease: 5-year follow-up of the randomised, clinical SYNTAX trial. Lancet 2013;381:629-38.

3. Zipes D, Libby P, Bonow R, et al. Braunwald's Heart Disease: A Textbook of Cardiovascular Medicine. 11th ed. Philadelphia, PA: Elsevier/Saunders; 2018.

4. Hara H, Nakamura M, Palmaz JC. Role of stent design and coatings on restenosis and thrombosis. Adv Drug Deliv Rev 2006;58:377-86.

5. Abizaid A, Sousa AGMR, Abizaid AS, et al. Sirolimus-eluting stents inhibit neointimal hyperplasia in diabetic patients: Insights from the RAVEL Trial. Eur Heart J 2004;25:107-12.

6. Tanabe K, Serruys Patrick W, Grube E, et al. TAXUS III Trial. Circulation 2003;107:559-64.

7. Carter AJ, Aggarwal M, Kopia GA, et al. Long-term effects of polymer-based, slow-release, sirolimuseluting stents in a porcine coronary model. Cardiovasc Res 2004;63:617-24. 
8. Nakazawa G, Finn AV, Joner M, et al. Delayed arterial healing and increased late stent thrombosis at culprit sites after drug-eluting stent placement for acute myocardial infarction patients: an autopsy study. Circulation. 2008;118:1138-45.

9. Finn AV, Nakazawa G, Joner M, et al. Vascular responses to drug eluting stents: importance of delayed healing. Arterioscler Thromb Vasc Biol 2007;27:1500-10.

10. Cook S, Ladich E, Nakazawa G, et al. Correlation of intravascular ultrasound findings with histopathological analysis of thrombus aspirates in patients with very late drug-eluting stent thrombosis. Circulation 2009;120:391-9.

11. Joner M, Finn AV, Farb A, et al. Pathology of drugeluting stents in humans: delayed healing and late thrombotic risk. J Am Coll Cardiol 2006;48:193202.

12. Wilson GJ, Nakazawa G, Schwartz RS, et al. Comparison of inflammatory response after implantation of sirolimus-and paclitaxel-eluting stents in porcine coronary arteries. Circulation 2009;120:141-9.

13. Smits PC, Hofma S, Togni M, et al. Abluminal biodegradable polymer biolimus-eluting stent versus durable polymer everolimus-eluting stent (COMPARE II): a randomised, controlled, noninferiority trial. Lancet 2013;381:651-60.

14. Lemos PA, Chandwani P, Saxena S, et al. Clinical outcomes in 995 unselected real-world patients treated with an ultrathin biodegradable polymercoated sirolimus-eluting stent: 12-month results from the FLEX Registry. BMJ open 2016; 6:e010028.

15. Taherinia A, Ahmadi K, Bahramian $\mathrm{M}$, et al. Diagnostic value of standard electrocardiogram in acute right ventricular myocardial infarction. Eur J Transl Myol 2019;29(2):8184. doi: 10.4081/ejtm. 2019.8184.

16. Win HK, Caldera AE, Maresh K, et al. Clinical Outcomes and Stent Thrombosis Following OffLabel Use of Drug-Eluting Stents. JAMA 2007;297:2001-9.

17. Beohar N, Davidson CJ, Kip KE, et al. Outcomes and Complications Associated With Off-Label and Untested Use of Drug-Eluting Stents. JAMA 2007;297:1992-2000.

18. Marroquin OC, Selzer F, Mulukutla SR, et al. A Comparison of Bare-Metal and Drug-Eluting Stents for Off-Label Indications. New England Journal of Medicine 2008;358:342-52.

19. Dibra A, Kastrati A, Alfonso F, et al. Effectiveness of Drug-Eluting Stents in Patients With Bare-Metal In-Stent Restenosis. Meta-Analysis of Randomized Trials 2007;49:616-23.

20. Finn AV, Nakazawa G, Joner M, et al. Vascular Responses to Drug Eluting Stents. Arterioscler Thromb Vasc Biol 2007;27:1500-10.
21. Cook S, Ladich E, Nakazawa G, et al. Correlation of intravascular ultrasound findings with histopathological analysis of thrombus aspirates in patients with very late drug-eluting stent thrombosis. Circulation 2009;120:391-9.

22. Joner M, Finn AV, Farb A, et al. Pathology of DrugEluting Stents in Humans. Delayed Healing and Late Thrombotic Risk 2006;48:193-202.

23. Windecker S, Serruys PW, Wandel S, et al. Biolimus-eluting stent with biodegradable polymer versus sirolimus-eluting stent with durable polymer for coronary revascularisation (LEADERS): a randomised non-inferiority trial. Lancet 2008;372: 1163-73.

24. Stefanini GG, Kalesan B, Serruys PW, et al. Longterm clinical outcomes of biodegradable polymer biolimus-eluting stents versus durable polymer sirolimus-eluting stents in patients with coronary artery disease (LEADERS): 4 year follow-up of a randomised non-inferiority trial. Lancet 2011;378: 1940-8.

25. Daemen J, Wenaweser P, Tsuchida K, et al. Early and late coronary stent thrombosis of sirolimuseluting and paclitaxel-eluting stents in routine clinical practice: data from a large two-institutional cohort study. Lancet 2007;369:667-78.

26. Räber L, Wohlwend L, Wigger M, et al. Five-Year Clinical and Angiographic Outcomes of a Randomized Comparison of Sirolimus-Eluting and Paclitaxel-Eluting Stents. Circulation 2011;123: 2819-28.

27. Smits PC, Kedhi E, Royaards KJ, et al. 2-Year Follow-Up of a Randomized Controlled Trial of Everolimus- and Paclitaxel-Eluting Stents for Coronary Revascularization in Daily Practice. COMPARE (Comparison of the everolimus eluting XIENCE-V stent with the paclitaxel eluting TAXUS LIBERTÉ stent in all-comers: a randomized open label trial). J Am Coll Cardiol 2011;58:11-8. doi: 10.1016/j.jacc.2011.02.023. Epub 2011 Apr 21.

28. Stone GW, Rizvi A, Sudhir K, et al. Randomized Comparison of Everolimus- and Paclitaxel-Eluting Stents. 2-Year Follow-Up From the SPIRIT (Clinical Evaluation of the XIENCE V Everolimus Eluting Coronary Stent System) IV Trial 2011;58:19-25.

29. Byrne RA, Kufner S, Tiroch K, et al. Randomised trial of three rapamycin-eluting stents with different coating strategies for the reduction of coronary restenosis: 2-year follow-up results. Heart 2009;95:1489-94.

30. Byrne RA, Kastrati A, Massberg S, et al. Biodegradable Polymer Versus Permanent Polymer Drug-Eluting Stents and Everolimus- Versus Sirolimus-Eluting Stents in Patients With Coronary Artery Disease. 3-Year Outcomes From a Randomized Clinical Trial 2011;58:1325-31. 
31. Ormiston JA, Serruys PW, Regar E, et al. A bioabsorbable everolimus-eluting coronary stent system for patients with single de-novo coronary artery lesions (ABSORB): a prospective open-label trial. Lancet 2008;371:899-907.

32. Wijns W, Vrolix M, Verheye S, et al. Randomised study of a bioabsorbable polymer-coated sirolimuseluting stent: results of the DESSOLVE II trial. EuroIntervention 2015;10:1383-90.
33. Abhyankar A, Kaul U, Sinha SK. Seven-year clinical outcomes in patients undergoing percutaneous coronary intervention with biodegradable polymer coated sirolimus-eluting stent: Results from a single-center real-world experience. Indian Heart Journal 2018;70:S280-S4.

Submissions: April 13, 2019

Revision received: April 24, 2019

Acceptance: April 25, 2019 